\title{
LA FUNDACIÓN DE LA MADRASA AL-ADĀB POR LA ASOCIACIÓN DE ULEMAS MUSULMANES ARGELINOS EN LA CIUDAD DE HENNAYA (TREMECÉN) EN 1950
}

\author{
SARRA IKRAM HADEF \\ Universidad Abou Bakr Belkaid de Tremecén
}

I. LA ACCIÓN LOCAL DE LA ASOCIACIÓN DE ULEMAS MUSULMANES ARGELINOS

La colonización francesa de Argelia se extendió desde 1830 hasta 1962. Durante este tiempo, Argelia fue asimilada en tres regiones o departamentos franceses, formando parte integral de la metrópoli. Como tal, fue el destino de cientos de inmigrantes franceses, españoles, italianos, alemanes, etc., llamados pieds noirs. Durante ciento treinta y dos años la dominación francesa consideró el territorio y la población francesa en Argelia como una importante minoría europea.

Sin embargo, a partir de los años treinta, Argelia empezó a recuperar la conciencia de libertad, o a construir al menos una nacionalidad a la que aspirar. El partido FLN (Frente de Liberación Nacional) fue fundado y dirigido por figuras carismáticas: Ahmad Ben Bella y Muhammad Boudiaf, entre otros. Este grupo quería combatir el colonialismo a través de la resistencia armada ${ }^{1}$. No obstante existía otra manera de enfrentarse al colonizador, a través de la lucha intelectual dirigida por personajes como Aḥmad Ben Bādīs y al-Bašìr al-Ibrāhīmī, quienes fueron los fundadores de la Asociación de ulemas musulmanes argelinos / جمعية العلماء المسلمين الجزائريين (AUMA).

La creación de la Ŷam'iyya al-úlamä’ al-muslimīn al-yazâa’iriyyin se produjo el 5 de mayo de 1931 por Ben Bādīs, al-'Ukbī y al-Ibrāhīmī, asociación que realizó una labor decidida contra la religiosidad popular, la adherencia a cultos sufies y la agresión cultural francesa, con el fin de dar argumentos al nacionalismo argelino. Su famoso

${ }^{1}$ Véase Mohammed Harbi y Gilbert Meynier, Le FLN, document et histoire: 1954-1962, París, Fayard, 2004. 
lema era: "el Islam es nuestra religión, el árabe nuestra lengua, y Argelia nuestra patria”, al-Islām dìnu-nā, al-'arabiyya lugatu-nā wa-l$\hat{Y} a z \bar{a} i r$ watanu-nā. Su principal objetivo era luchar contra la ignorancia en los pueblos argelinos, renovar el Islam y la lengua árabe clásica dentro de la sociedad como lengua materna²

Queremos presentar en el presente artículo el valor de la AUMA y su importancia, precisando la labor del šayj al-Bašīr al-Ibrāhīmī, quien luchó contra el colonialismo de forma cultural. Él fue quien sucedió a Ben Bādīs en tal cometido, cuando fue elegido como el nuevo presidente de la asociación en las elecciones celebradas tras el fallecimiento de Ben Bādīs en 1940.

\section{LA CIUDAD DE HENNAYA}

Hennaya es una parte de Tremecén, está situada en el límite norte de las comunidades de Remchi y Ain Yusef, al este con los municipios de Amier y Tremecén, al oeste con Zenata y el sur con Beni Mester. La historia dice que el pueblo fue creado en 1851 por el colono Eugène Étienne (1844-1921), que fue el primer nombre que recibió la localidad.

Hennaya fue un lugar favorecido por el colonialismo francés, donde se encontraban numerosas casas de colones franceses y pieds noirs. Existía además la iglesia principal de la zona, la congregación misionera de Nuestra Señora de Apóstoles. Por otro lado y antes de la llegada del movimiento reformista, el Islam que se practicaba se asentaba obviamente en prácticas tradicionales en mayor o menor medida alteradas por la presencia cultural del colonialismo.

\section{LA ACCIÓN NACIONAL DE AL-BAŠĨR AL-IBRĀHĪMĪ}

Muḥammad al-Bašīr al-Ibrāhīmī b. al-Sa'dī b. 'Umar al-Ibrāhīmī fue un activista argelino, considerado uno de los principales predicadores salafíes de la religión islámica durante el colonialismo francés. Nació en el este de Argelia en la ciudad de Setif en 1306 H.1889 d.C. Pertenecía a la tribu de rirra, del clan de ūlād Ibrāhīm b. Yahyà b. Masāhal. Fue discípulo de los siguientes eruditos: Mạ̣mūd

${ }^{2}$ Vid. Miguel Cruz Hernández, Historia del pensamiento en el mundo islámico. El pensamiento islámico desde Ibn Khaldun hasta nuestros dias, Madrid, Alianza, 1996, vol. 3, pp. 778-779. 
Šankitī, Ḥamdān al-Wanīlī, y Ben Mubārak al-Zāwīī. En 1911 se trasladó a Oriente, residió en Medina en 1917, y después se desplazó a Damasco en 1921. Cuando llegó a Argelia, pensó crear un nuevo movimiento intelectual con Ben Bādīs, con miles de estudiantes, hasta que se fundó la AUMA en 1931.

El šayj al-Ibrāhīmī siguió desarrollando el movimiento en todas las regiones de Argelia después de su elección. Fue detenido entonces por los franceses y encarcelado en el desierto hasta que obtuvo la liberación. Desde ese momento estableció setenta y tres madrasas ${ }^{4}$, para las cuales había redactado textos educativos y pedagógicos. Poco a poco fue trasladándose a los pueblos de Argelia y estableciendo otras escuelas gracias al apoyo de los colegas de la asociación en cada región, hasta su llegada a Tremecén, en particular al pueblo de Hennaya en $1950 .{ }^{5}$ La juventud y la intelectualidad de la localidad de Hennaya se organizó entonces para fundar una Madrasa al-Adāb/ ("Escuela de Letras") dentro de una mezquita de nueva planta.

Vamos a pasar a relatar la intrahistoria de este acontecimiento y de sus protagonistas, un caso concreto de intervención de la AUMA en un pueblo argelino con el fin de formar a la juventud que debía de construir la nueva nación. Para ello intervenían autoridades locales, como al-Haŷŷ̀i Būazzza para el caso de Hennaya.

\section{LA ACCIÓN LOCAL DE AL-ḤĀŶYȲi BƯ'AZZA}

Al-Ḥaŷŷ̄i Hādaf Bū'azza nació el 24 de febrero de 1912 y murió en 15 de junio de 2012. Sus padres pertenecían al pueblo de Beni Mester en Tremecén. Fue uno de los principales participantes de la AUMA en Hennaya. Al mismo tiempo, conoció al-Ibrāhīmī en los años de la fundación de la madrasa. Entre sus cualidades era amigo íntimo de los cristianos de Hennaya, los hermanos y hermanas

${ }^{3}$ Cf. Mohand-Amer Amar y Benzenine Belkacem, Le Maghreb et l'indépendance de l'Algérie, Orán, Karthala, 2012, p. 108.

${ }^{4}$ Escuelas en lengua castellana.

${ }^{5}$ Cf. Abdelhafid Amokrane El Hassani, Mémoires de combat, Argel, Dar al Oumma, 1998, p. 15 . 
misioneras de la Congregación Nuestra Señora de Apóstoles ${ }^{6}$. En 1957 fue encarcelado por las tropas francesas en Hennaya con sus compañeros, sin embargo, pudo huir de la cárcel hacia Marruecos por la frontera. Volvió definitivamente junto a su familia después de la independencia. Tuvo cinco hijas, alumnas de la Madrasa al-Adāb y después las primeras profesoras en las escuelas de Hennaya tras la independencia.

\section{LA CONSTRUCCIÓN DE LA MADRASA AL-ADÄB}

La primera etapa fue la fundación de un club social en 1945. La segunda, los eruditos empezaron a comprar la tierra en la avenida de Hennaya, a partir del año de 1948; hasta llegar a la última fase, la compra definitiva del solar para edificar un edificio de nueva planta. El propietario era Muḥammad b. Dīm'rād, quien recibió una carta por al-Bašīr al-Ibrāhīmī, cuando deseaba vender el lote a un colono de origen judío. Así decía la carta:

Hijo mío, tiene que saber que todo se acaba, la vida, la gente y el dinero, si va a venderla a esa persona, va a hacer un gran error a Dios y a la gente, si va a venderla a la Asociación de ulemas musulmanes, va a ganar el amor de Dios?

La apertura de la Madrasa al-Adāb tuvo lugar el día 17 de junio de 1950 d.C. / 1 de ša'bān de 1637 H. Fue un gran acontecimiento para la ciudad de Hennaya. Al-Bašīr al-Ibrāhīmī participó junto con sus compañeros en el día de la apertura visitando toda la localidad de Hennaya. Los testigos afirmaban que, a pesar de las dificultades, se habían mantenido unidos en este periodo. Los eruditos locales y alumnos de la madrasa acogieron al-Bašīr al-Ibrāhīmī, cantando la canción de la AUMA:

${ }^{6}$ Es un grupo internacional de cristianos, forma un centro de nueva fundación, cuyo carisma es la misión siempre misionera. La congregación fue fundada por el padre Planque Augustin, quien era el superior general de la Sociedad de las Misiones Africanas SMA. Véase nuestro trabajo "Convivencia entre las hermanas misioneras la aldea de Hennaya después de 1962 hasta hoy día”, en Revue d'antrhopologie des religions, Universidad de Tremecén, 2015, núms. 17-18, p. 11.

${ }^{7}$ Archive départemental, Tremecén, div, 1850. núm 264. 


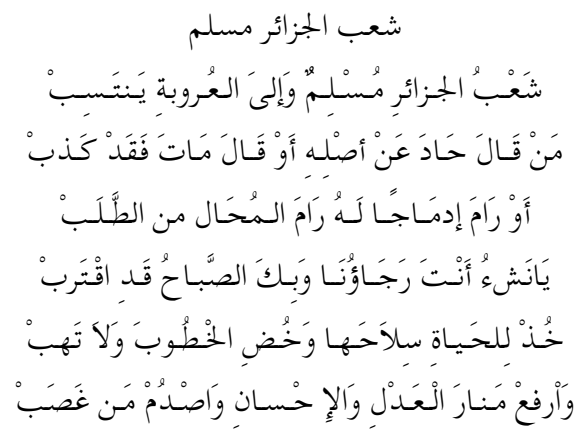

El pueblo de Argelia es musulmán.

El pueblo de Argelia es musulmán y en arabismo está afiliado.

Quien dijo que se habia alejado de su origen o dijo que se habia muerto, es mentiroso o quiere ser convidado, su voluntad es una solicitud imposible.

¡Joven! Es nuestra esperanza, y por su intercambio, consigo, la mañana se aproxime arranque esta vida sus armas, y enfréntese a retos sin miedo.

Y eleve el faro de la justicia, y la bondad, y se alce frente a la injusticia ${ }^{8}$.

Destaca en la fundación de la Madrasa al-Adāb la personalidad de Muḥammad Lablaq, de la cual al-Ibrāhīmī dijo en sus escritos: "iQue Dios haga en cada pueblo Lablak!". Destaca igualmente Hādaf Bū'azza, del que dijo que era pacífico, los colonos le respetaban en el pueblo debido a su amistad con misioneros de Hennaya, haciendo pactos con ellos para que no hubiera problemas con la AUMA.

La ciudad de Hennaya se presentaba como modelo para todas las regiones argelinas. Sin embargo, a partir de 1956, los colonos empezaron a atacar a los ulemas, cerrando la mezquita. Las tensiones por ambos lados fueron en aumento hasta lo insostenible. Hādaf Bū'azza fue presionado hasta el punto de que tuvo que huir de la cárcel poco antes de su ejecución. Comenzó entonces la revolución en la colonia norteafricana, entre la administración de la metrópoli y una población indígena que deseaba otro modelo político.

VI. DISCURSO DE AL-IBRĀHĪMĪ EN HENNAYA

${ }^{8}$ Los versos pertenecen al poema $\check{S}^{\prime}{ }^{‘} b u$ al-ŷazầirì muslimūn, escrito por Ahmād b. Bādīs. Traducción nuestra. 
Al-Ibrāhīmī inició su discurso de inauguración de la madrasa con la basmala, junto a algunas aleyas coránicas de la azora "El levantamiento", al-Qiyāma. Después hizo una comparación entre la sunna de la civilización y la sunna cósmica, y la necesidad del desarrollo científico. Comenta la celebración centenaria llevada a cabo por Francia con motivo de los cien años de su dominación, mostrando a los argelinos el desconocimiento de su propio país. Argelia sufre una enfermedad, y el enfermo necesita medicamentos, que son la reforma y la ciencia. Habla sobre las causas que producen el atraso de la nación, la ignorancia, la injusticia social y los atropellos; otra cosa más peligrosa es la fitna entre los sabios, la fragmentación de un programa unitario, fragmentación fomentada por Francia durante años para la perpetuación del colonialismo en Argelia. También presenta la importancia de la fe, el estudio del Corán, interpretando las aleyas como guía de la ciencia y puerta para el descubrimiento del mundo por sus explicaciones.

En la tercera parte del discurso aconseja la comprensión de la vida y la realidad en la que vivimos para luchar contra el analfabetismo y, ciertamente, saber bien la lengua materna, sin duda saber bien el árabe. Señala entonces una serie de pasos: lo primero es la ciencia, que es algo que se consigue con esfuerzo, lo segundo es el trabajo, el bueno y el propio, lo tercero es volver al libro de Dios, al Corán y la sunna del Profeta Muhammad. Añade, igualmente, que es necesario aprender del progreso de los países colonizadores, tomando sus elementos positivos, como la ciencia y el desarrollo.

Dice que la vida sin felicidad no tiene valor; la persona tiene que pedirle cosas a la vida para que pueda alcanzar la felicidad; hay que cambiar la vida y olvidarse de las penas. En este sentido, afirma que el proyecto de Hennaya es símbolo de una vida feliz; las generaciones deben proteger y desarrollar esta gracia, aclarando que el poder viene por debilidad, por la debilidad de quien no asume las riendas de su propia vida. La participación colectiva en la construcción de la madrasa muestra la fuerza de voluntad de la comunidad. Hennaya se convierte así en una ciudad de ciencia.

Al-Bašīr al-Ibrāhīmī interpela constantemente a la juventud, pues son los jóvenes el futuro de cualquier nación. Así llama: “¡Vosotros 
hijos, vosotros jóvenes!" (ايهـا الشـباب ايهـا الابنـاء). La presencia de los jóvenes es importante en la transición del estado, las generaciones próximas tienen que luchar contra el analfabetismo para el desarrollo de Argelia, como señala en esta alocución:

$$
\begin{aligned}
& \text { ليت شـعري مـالا يـورث لابنائنـا لهـده الحيـاة لقسـميها المادي و المعنسوي، ان نسورثهم }
\end{aligned}
$$

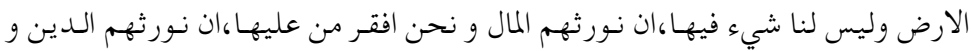

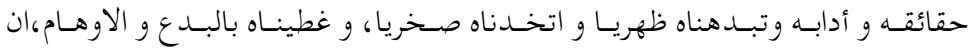

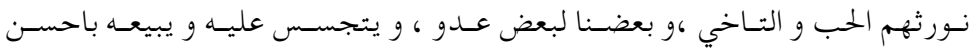

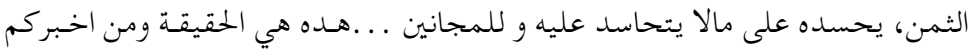

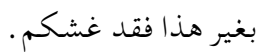

Espero que nuestros hijos hereden al menos mis versos en esta vida para su desarrollo físico y moral, ya que no heredarán la patria, pues nada hay en ella, no heredarán el dinero, pues somos pobres en ella, no heredarán la religión, su realidad y ciencia, pues la hemos reducido a sortilegios, no heredarán el amor y la solidaridad, pues somos enemigos de nosotros mismos, uno espía al otro y le vende al mejor postor. Esto es la verdad, y quien te diga lo contrario, te ha engañado.

Termina el discurso con el siguiente texto:



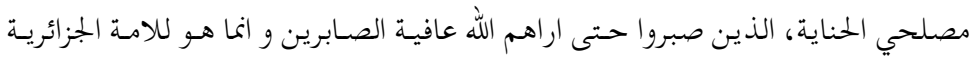

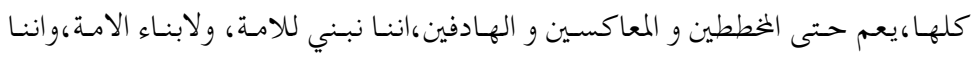

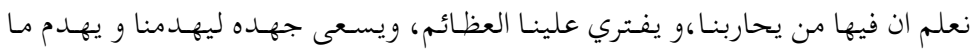

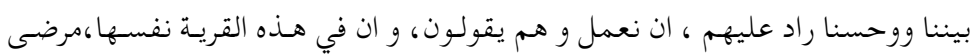

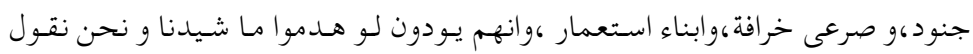

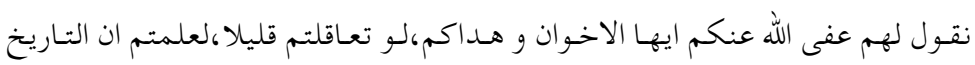

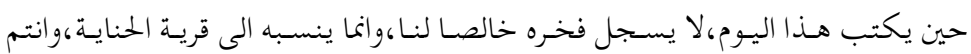


El orgullo de este día no pertenece sólo a este pueblo, sino que es el orgullo de la patria argelina, y no es sólo el orgullo de los eruditos de Hennaya, que han tenido la paciencia hasta que Dios le mostró el bienestar del paciente, sino es de todo el país de Argelia; también, es de los constructores, hemos construido para la nación, e hijos de la nación, y sabemos que hay enemigos que nos luchan, haciendo esfuerzo para hacernos caer; la mejor respuesta a ellos es trabajar y dejarles hablar; en este pueblo hay enfermedad de soldados, de ignorancia de la gente, de ser hijos del colonialismo, quieren hacer caer todo lo que hemos establecido, vamos a decirles que Dios os perdone, hermanos nuestros. Que se tranquilicen, van a saber que la historia ha grabado este día en su memoria, sin embargo, no ha grabado nuestro orgullo, sino ha grabado el nacimiento de Hennaya, de ustedes como pueblo?.

En conclusión, la acción de la AUMA comenzó a ser importante a mediados del siglo XX para difundir las ideas de la nabda islámica en las zonas interiores de Argelia, construyendo en consecuencia unas conciencias identitarias que, evidentemente, cohesionaban una afirmación más sólida frente al discurso del colonizador. El resultado sin embargo acabó con una reacción extremadamente violenta por parte de la metrópoli, y la radicalización de los discursos, con un resultado funesto para el desarrollo de la educación y el saber en ambos lados.

\footnotetext{
9 Textos extraídos del Archivo municipal de Hennaya: “Al-Bašīr al-Ibrahīmī en el día de la apertura de la mezquita y la madrasa”, Hennaya, 17 de junio de 1950 d.C. / 1 de šabān de 1637 H. Traducción nuestra.
} 
APÉNDICE ICONOGRÁFICO:

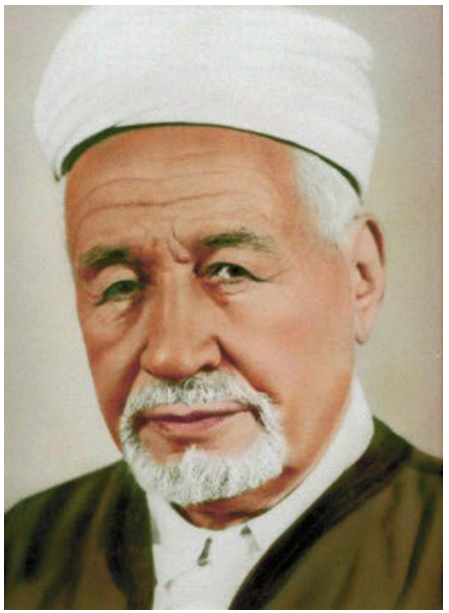

al-Bašīr al-Ibrāhīmī

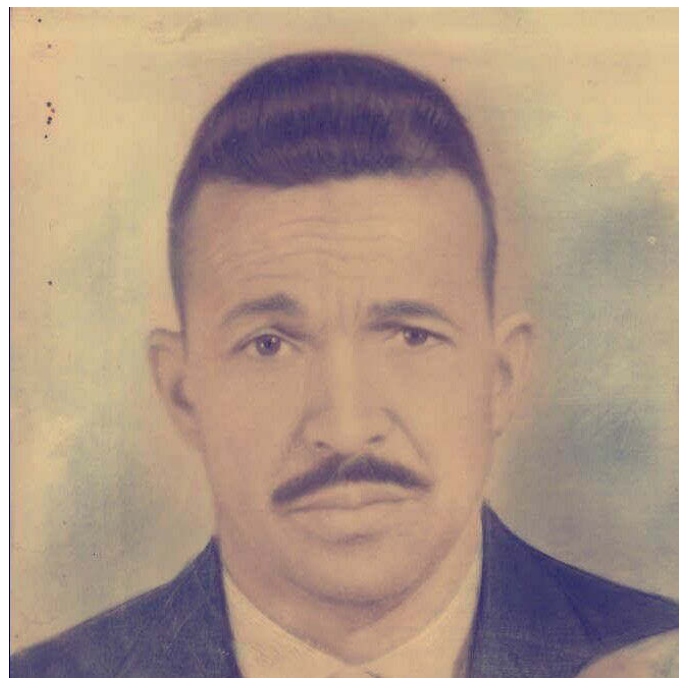

Ḥādaf Bū'azza 


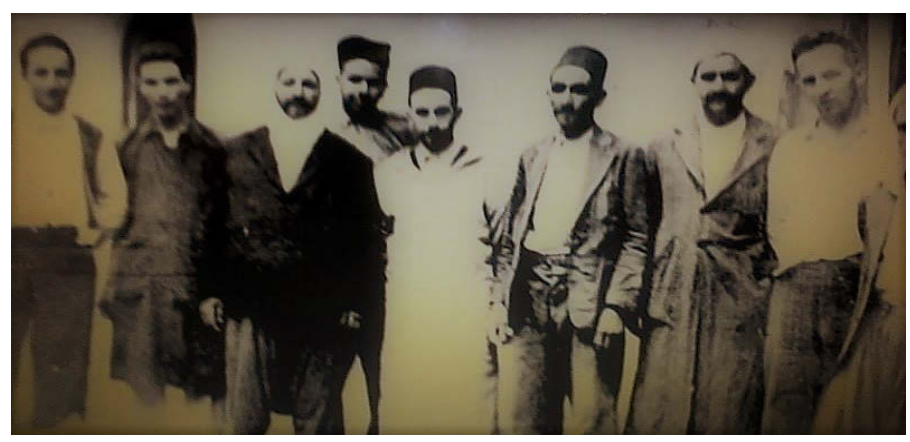

Grupos de eruditos de Hennaya

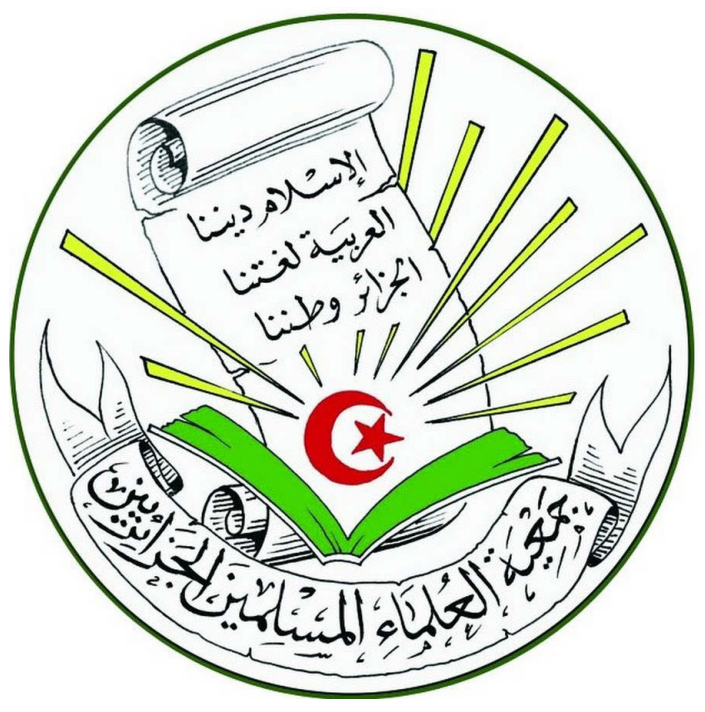

Símbolo de la Asociación de ulemas 


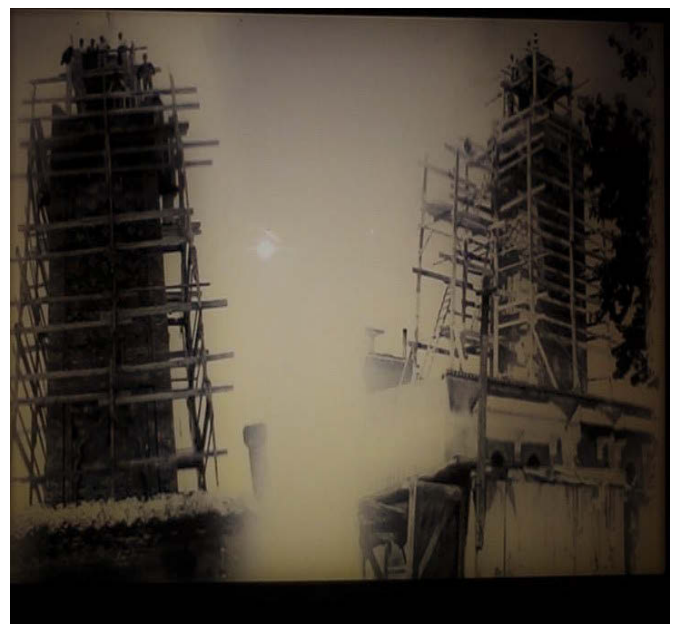

Construcción de la mezquita

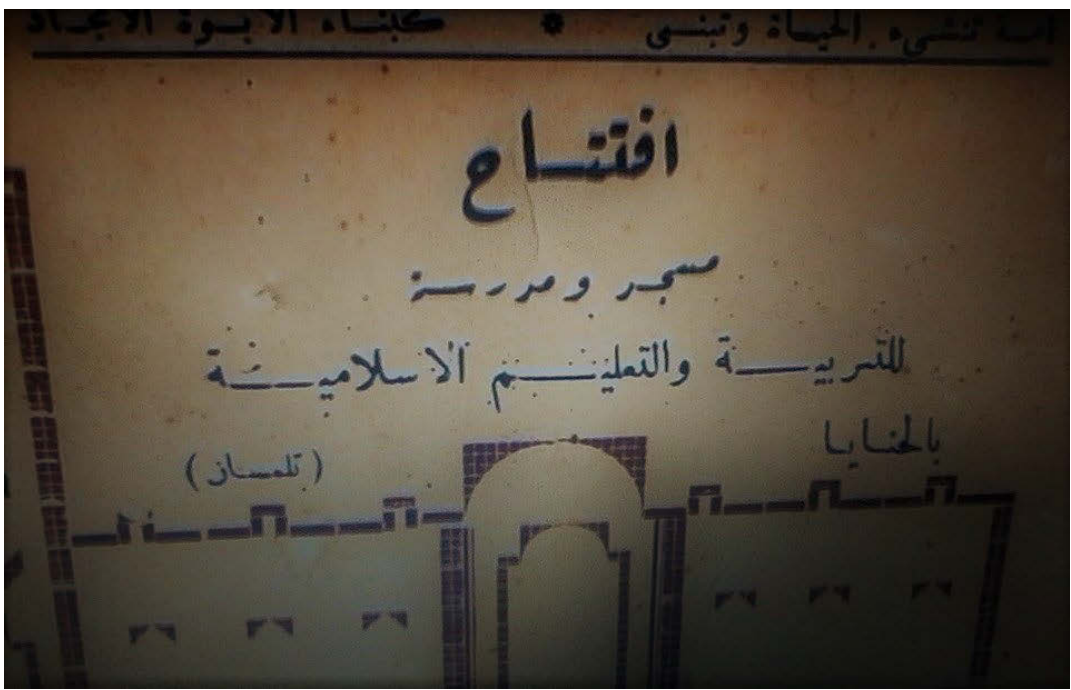

Anuncio de la apertura de la mezquita y madrasa de enseñanza y educación islámica 


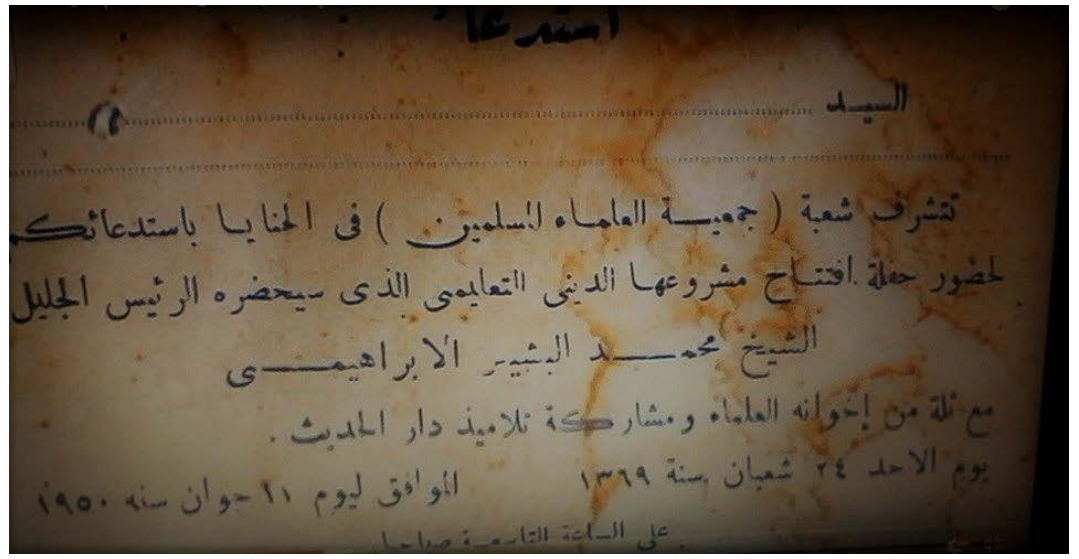

Carta de invitación

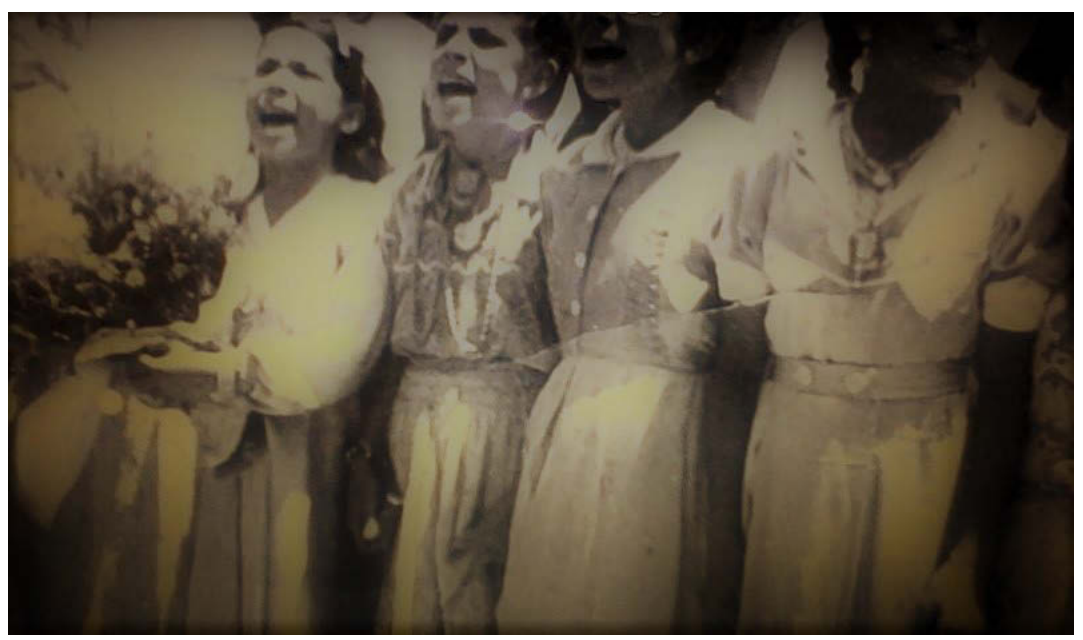

Alumnas en Hennaya 


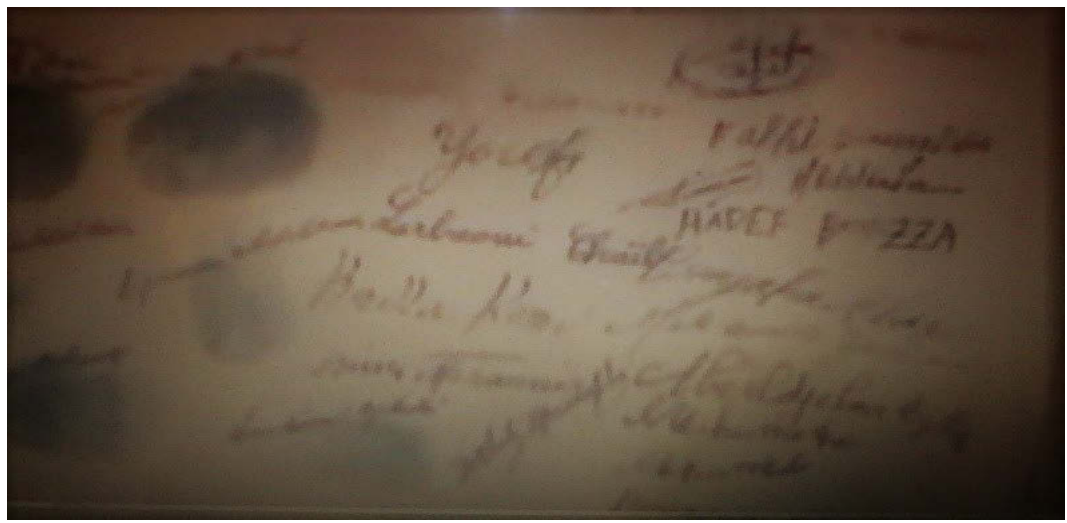

Firmas de los principales participantes en el establecimiento de la mezquita y la madrasa

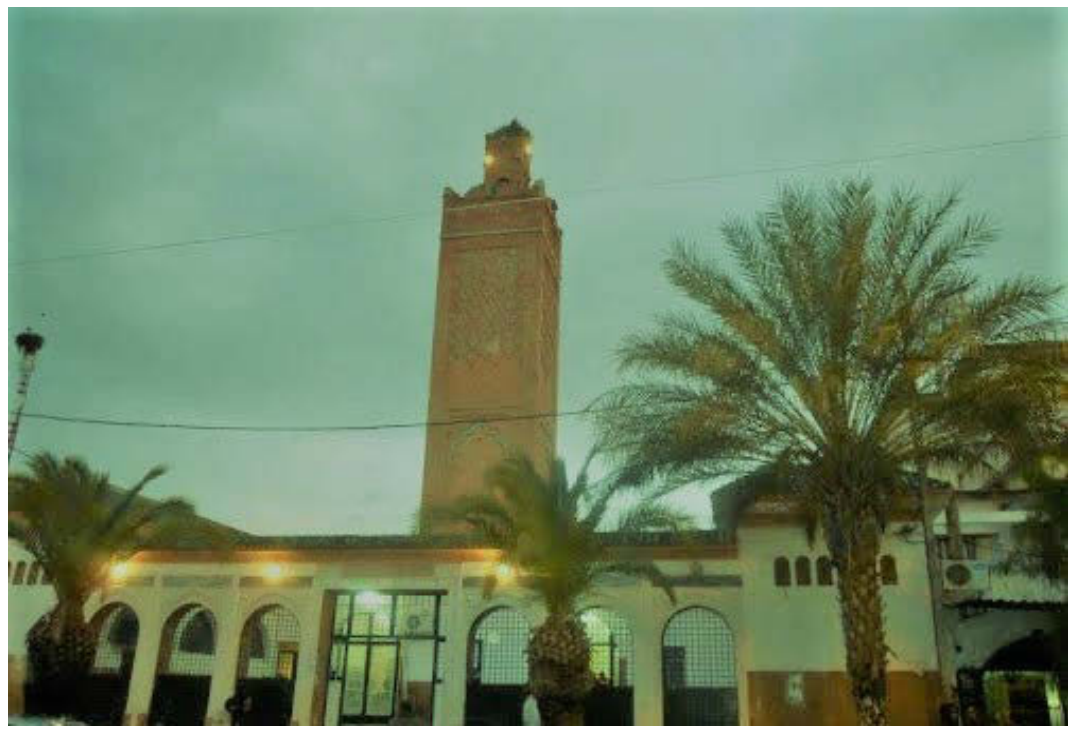

La mezquita y madrasa de Hennaya en la actualidad 